\title{
Psychosis associated with epilepsy: significance of the laterality of the epileptogenic lesion
}

\author{
IRA SHER WIN \\ From the Neurophysiology Unit, Research Service, ENRM Veterans Hospital, Bedford, Massachusetts, and \\ the Department of Neurology, Harvard Medical School, Boston, Massachusetts
}

SUMMARY The psychiatric histories in a group of patients who had previously undergone temporal lobectomy for intractable epilepsy, were analysed for the occurrence of psychosis. The data suggest that epileptic patients with left temporal lobe lesions are especially disposed to develop a schizophrenic-like psychosis.

In an earlier study of patients selected for the concordance of medically intractable epilepsy and behaviour disorder, we reported that $15 \%$ of the patients demonstrated a schizophrenic-like psychosis at some point in their illness. ${ }^{1}$ All of the psychotic patients appeared to have had left temporal lobe epileptogenic lesions (TLEL) based on pneumoencephalographic and electroencephalographic (EEG) findings. It is difficult to establish a relationship between a type of psychiatric illness and the laterality of an epileptogenic lesion, for conventionally recorded EEG, or even depth recorded interictal data, ${ }^{23}$ are unreliable. We have examined the relative frequency of psychosis in a group of patients with unilateral epileptogenic lesions established by depth recorded ictal episodes, so as to justify a temporal lobectomy.

\section{Patients and methods}

Details of the evaluation of these patients for possible "seizure-surgery" have been reported elsewhere. ${ }^{4}$ In those patients in whom a unilateral temporal lobe lesion was identified, Dr Paul Crandall performed an en bloc anterior temporal lobectomy, which extended only $1 \mathrm{~cm}$ more posteriorly in the minor

* This work was conducted at the Reed Neurological Research Center (UCLA); and was supported by USPHS Grant 02808 and the Veterans Administration.

A ddress for reprint requests: Dr Ira Sherwin, ENRM Veterans H ospital, Bedford, Massachusetts 01730, USA.

Accepted 26 August 1980 hemisphere. Only those patients who were diagnosed as psychotic were accepted for the present study, which was retrospective. No attempt to "validate" the psychiatric diagnosis was made.

\section{Results}

The composition of the series is shown in the table (part A). Only the 63 cases (part B) warranting temporal lobectomy, were analysed further.

Right temporal lobe lesions predominated $\left(x^{2}=13.65, \mathrm{p}<0.001\right)$ in contrast to the opposite finding in our earlier study. The principal selection criteria in that study was the coexist-

Table

\begin{tabular}{|c|c|c|c|}
\hline \multicolumn{3}{|c|}{ A: Series composition } & Number of patients \\
\hline \multicolumn{3}{|c|}{$\begin{array}{l}\text { Lost to follow-up or dead } \\
\text { Cases remaining for analysis } \\
\text { Temporal lobe epileptogenic lesions } \\
\text { Unilateral (lobectomy) } \\
\text { Bilateral (depth electrodes only) } \\
\text { Other epileptogenic lesions } \\
\qquad \text { B: Laterality and sex }\end{array}$} & 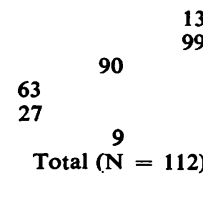 \\
\hline $\operatorname{Sex}$ & Left $(\mathbf{N}=17)$ & Right $(\mathbf{N}=46)$ & Total $(N=63)$ \\
\hline $\begin{array}{l}\text { Male } \\
\text { Female }\end{array}$ & $\begin{array}{r}13 \\
4\end{array}$ & $\begin{array}{l}23 \\
23\end{array}$ & \\
\hline \multicolumn{4}{|c|}{ C: Psychosis and laterality } \\
\hline Lobectomy & $\begin{array}{l}\text { Psychotic } \\
(\mathrm{N}=7)\end{array}$ & $\begin{array}{l}\text { Non-psychotic } \\
(\mathrm{N}=54)\end{array}$ & Total $(N=61)$ \\
\hline $\begin{array}{l}\text { Right } \\
\text { Left }\end{array}$ & $\begin{array}{l}2 \\
5\end{array}$ & $\begin{array}{l}44 \\
10\end{array}$ & \\
\hline
\end{tabular}


ence of severe behaviour disorder. However, in the epilepsy programme from which the current sample was drawn, a deliberate attempt has been made to exclude patients with a severe behaviour disorder or active psychosis, at the time of intake. This was necessary for the depth electrode studies.

Left and right-sided temporal lobe lesions tended to be unequally distributed amongst the sexes (Fisher Exact Probability=0.053). The Binomial Test (assuming no $a$ priori laterality bias) revealed that the left/right difference was not significant for males, but for females it was $(p<0.001)$. The under-representation of females with left temporal lobe lesions is what might have been anticipated when psychotic patients were excluded if, as Taylor ${ }^{5}$ has postulated, this is the group most at risk for developing the schizophrenic-like psychosis. Despite this attempted exclusion of patients with active psychosis from the present series, we found seven cases who were diagnosed as having been psychotic. (Two other patients (with left temporal lobectomies) had histories suggestive of a paranoid schizophreniclike psychosis, but such a diagnosis had not been recorded, so they were not included in the subsequent analysis).

Of these seven cases (mean age at onset of seizures, $10 \cdot 2$ years). six were diagnosed as having had a paranoid or schizophrenic type of psychosis. Of the six, one had undergone a right and five a left temporal lobectomy. Case number seven. (right temporal lobectomy) was diagnosed as having had a schizo-affective psychosis with marked depressive features. The relative frequencies of left- and right-sided temporal lobe lesions in the psychotic and non-psychotic groups are shown in part $\mathrm{C}$ of the table, and differ significantly (Fisher Exact Probability=0.0077).

Six of these seven cases were rendered seizure free (post-operative follow-up $>5$ years); and case number seven had only occasional seizures, that is less than four a year. Despite these excellent results, indicating accurate lateralisation of the epileptogenic lesions, the psychiatric picture did not improve substantially in any case. In one patient a full-blown paranoid schizophrenic-like psychosis appeared three years after his successful surgery. In two patients, the psychiatric features appeared to progress despite the relief of their seizures.

\section{Discussion}

The finding in the present study that patients with left temporal lobe epileptogenic lesions are especially disposed to develop a schizophreniclike psychosis reinforces our own earlier findings ${ }^{1}$ and those of Taylor. ${ }^{5}$ Also it is compatible with the finding of a high percentage of sinistrals amongst psychotic epileptics, ${ }^{6}$ ' which may indicate a left hemispheric lesion. Men predominated (but not significantly so) in our sample of psychotics. However, because of possible selection factors noted above, this is not necessarily incompatible with the suggestion ${ }^{5}$ that women may be at greater risk.

In addition to a correlation between a schizophrenic-like psychosis and left temporal lobe lesions, Flor-Henry ${ }^{8}$ reported that psychotic depressions tended to occur in patients with right temporal lobe lesions. In the present study the only psychotic reaction characterised by depression occurred in one of the patients with a right temporal lobe lesion. Although no conclusions can be drawn from this single case, it indicates the need for additional studies.

The prevalence of psychosis in our sample may have been overestimated or underestimated as a result of our decision to accept the previouslyrecorded psychiatric diagnoses. However, there is no reason to believe that the accuracy of those diagnoses should have systematically varied as a function of which temporal lobe was ultimately excised. The prevalence of $11 \%$ observed in this sample, however, is in remarkable agreement with a recent report ${ }^{9}$ in which three out of 32 "completely lateralised" temporal lobe epileptics, that is $11 \%$, had a schizophrenic-like psychosis (see also ref $10,13 \%$; ref $11,14 \%$ ).

This propensity for patients with left-sided temporal lobe lesions to develop a schizophreniclike psychosis challenges the current popular view that the psychopathology seen in epileptics is a non-specific reaction to having a stigmatising illness, ${ }^{12}$ to chronic anticonvulsant therapy, ${ }^{13}$ or to chronic illness per se. ${ }^{10}$ In the present study the psychosis associated with epilepsy, deliberately has been referred to as "schizophrenic-like" and not as schizophrenia, which it resembles in several ways. However, even if the two disorders should prove to share some common pathophysiological substrates, there is no reason why they should be identical. Slater et $a l^{14}$ noted that a distinguishing clinical feature in this disorder was the preservation of affect. In our cases other distinguishing features were that the psychosis often was more periodic, and that frequently it did not require the use of major tranquillisers and usually did not require chronic hospitalisation. Similar findings have been noted by others. ${ }^{15}$

Two other issues raised by these studies deserve 
mention. Falconer ${ }^{11}$ reported that the schizophrenic-like psychosis appeared to be associated with hamartomatous lesions. We and others ${ }^{16}$ have not been able to confirm this association. However, it may be that the more "sophisticated" mental mechanisms responsible for paranoid ideation, which are not operative in infancy may be mobilised in late-onset (hamartomatous), temporal lobe epilepsy. ${ }^{17}$ A last point requiring comment was our observation and that of others ${ }^{15}$ that the onset of psychosis might follow the surgical elimination of the seizures. It may be that the epilepsy protects against the emergence of a psychosis. ${ }^{18}$ However, such a mechanism would neither account for the majority of cases in which the psychosis appears in the course of the seizure disorder, nor for its long latency when appearing after operation. Alternatively it is possible that the psychoses might have developed, in time, had no surgery been performed in these cases.

The author is indebted to the staff of the UCLA Clinical Neurophysiology Program and in particular to Drs Paul Crandall and Richard Walters for their invaluable help. However, responsibility for the conclusions and any errors in this report rests solely with the author.

\section{References}

1 Sherwin I. Clinical and EEG aspects of temporal lobe epilepsy with behaviour disorder, the role of cerebral dominance. McLean Hosp J (special issue) 1977; June: 40-50.

2 Gloor P, Oliver A, Ives J. Prolonged seizure monitoring with stereotaxically implanted depth electrodes in patients with bilateral interictal temporal epileptogenic foci: How bilateral is bitemporal epilepsy? (Abstract) 10th Epilepsy International Symposium, Vancouver, Canada. 1978; 22.

3 Wieser HG, Bancaud J, Talairach J, Bonis A, Szilka G. Comparative value of spontaneous and chemically and electrically induced seizures in establishing the lateralisation of temporal lobe seizures. Epilepsia 1979; 20:47-59.

4 Walter RD. Tactical considerations leading to surgical treatment of limbic epilepsy. In: Brazier MAB, ed. Epilepsy its phenomena in man. New York: Academic Press, 1973: 99-119.

5 Taylor DC. Factors influencing the occurrence of schizophrenia-like psychosis in patients with temporal lobe epilepsy. Psychol Med 1975; 5: 249-54.

6 Kristensen O, Sindrup EH. Psychomotor epilepsy and psychosis. (I. Physical Aspects.) Acta Neurol Scand 1978; 57:361-9.

7 Jensen I, Larsen JK. Mental aspects in drug resistant temporal lobe epilepsy. (Abstract) 10th Epilepsy International Symposium, Vancouver, Canada. 1978; 196-7.

8 Flor-Henry P. Schizophrenic like reactions and affective psychoses associated with temporal lobe epilepsy: Etiological factors. Am J Psychiat 1969; 126:148-52.

9 Pritchard PB, Lombroso TL, McIntyre M. Psychological complications of temporal lobe epilepsy. Neurology (Minneap) 1980; 30:227-32.

10 Guerrant J, Anderson WW, Fischer A, Weinstein MR, Jaros RM, Deskins A. Personality in Epilepsy. Springfield, Ill: CC Thomas, 1962: 27-99.

11 Falconer MA. Temporal lobe resection for epilepsy and behavioural abnormalities. New Engl J Med 1973; 289:451-5.

12 Epilepsy Foundation of America. Basic statistics on the epilepsies. Philadelphia: FA Davis, 1975: $59-61$.

13 Reynolds EH. Discussion of: Interictal manifestations of complex partial seizures. In: Penry JK, Daly DD, eds. Advances in Neurology Vol 11. New York, Raven Press, 1977: 110.

14 Slater E, Beard AW, Glithero E. The schizophrenia like psychoses of epilepsy (i-v). $B r J$ Psychiatry 1963; 95:109-50.

15 Jensen I, Larsen JK. Mental aspects of temporal lobe epilepsy, followup of 74 patients after resection of a temporal lobe. J Neurol Neurosurg and Psychiatry 1979; 42:256-65.

16 Jensen I, Klinken L. Temporal lobe epilepsy and neuropathology. Histological findings in resected temporal lobes correlated to surgical results and clinical aspects. Acta Neurol Scand 1976; 54: 391-414.

17 Taylor DC. Aggression and epilepsy. J Psychosom Res 1969; 13:229-36.

18 Meduna L Von. General discussion of the cardiazol therapy. Am J Psychiat Suppl 1938; 94: 40-50. 